\title{
Mechanisms of reversible stretchability of thin metal films on elastomeric substrates
}

\section{Citation}

Lacour, Stéphanie P., Donald Chan, Sigurd Wagner, Teng Li, and Zhigang Suo. 2006.

"Mechanisms of Reversible Stretchability of Thin Metal Films on Elastomeric Substrates." Applied Physics Letters 88 (20): 204103. https://doi.org/10.1063/1.2201874.

\section{Permanent link}

http://nrs.harvard.edu/urn-3:HUL.InstRepos:41467478

\section{Terms of Use}

This article was downloaded from Harvard University's DASH repository, and is made available under the terms and conditions applicable to Other Posted Material, as set forth at http:// nrs.harvard.edu/urn-3:HUL.InstRepos:dash.current.terms-of-use\#LAA

\section{Share Your Story}

The Harvard community has made this article openly available.

Please share how this access benefits you. Submit a story. 


\title{
Mechanisms of reversible stretchability of thin metal films on elastomeric substrates
}

\author{
Stéphanie P. Lacour, ${ }^{\text {a) }}$ Donald Chan, and Sigurd Wagner \\ Department of Electrical Engineering, Princeton University, Princeton, New Jersey 08544 \\ Teng Li and Zhigang Suo \\ Division of Engineering and Applied Sciences, Harvard University, Cambridge, Massachusetts 02138
}

(Received 16 December 2005; accepted 22 March 2006; published online 16 May 2006)

\begin{abstract}
Gold films on an elastomeric substrate can be stretched and relaxed reversibly by tens of percent. The films initially form in two different structures, one continuous and the other containing tribranched microcracks. We have identified the mechanism of elastic stretchability in the films with microcracks. The metal, which is much stiffer than the elastomer, forms a percolating network. To accommodate the large elongation of the elastomeric substrate, the metal network twists and deflects out of the plane but remains bonded to the soft substrate. Consequently, the metal film experiences only small strains and deforms elastically without suffering fatigue. (C) 2006 American Institute of Physics. [DOI: 10.1063/1.2201874]
\end{abstract}

Freestanding metal thin films rupture when stretched beyond $1 \%-2 \%{ }^{1-3}$ A metal film bonded to a plastic substrate can sustain plastic deformation by tens of percent. ${ }^{4,5}$ The film fatigues if subjected to cyclic loading. However, a metal film on an elastomeric substrate can be stretched repeatedly by tens of percent over hundreds of cycles without fatigue and remain electrically conducting. ${ }^{6-8}$ Here we provide an explanation for this reversible stretchability of gold films on elastomeric substrates.

Thin films of gold deposited on a polydimethylsiloxane (PDMS) substrate may be either continuous and wavy, or contain built-in tri-branched microcracks with lengths of micrometers and less. ${ }^{9}$ We focus on the mechanisms for stretchability of such microcracked films. These films have relatively high electrical resistivity but are most stretchable. ${ }^{7}$ The ligaments in the gold film form a percolating network that ensures electrical continuity. When the elastomeric substrate is stretched, the gold network twists and deflects out of the plane, so that a large elongation of the elastomeric substrate induces only small and elastic strains in the gold network. From these results we derive a general principle for designing "elastic" metallic conductors on elastomeric substrates. When integrated with thin film transistors, these stretchable conductors will enable elastic electronic surfaces ranging from conformal displays ${ }^{10}$ to prosthesis compatible to biological tissue. ${ }^{11-13}$

Gold stripes are fabricated directly on a $1 \mathrm{~mm}$ thick PDMS substrate using an all-dry process. The $16 \mathrm{~mm}$ long, $200 \mu \mathrm{m}$ wide stripes terminating in $2 \times 2 \mathrm{~mm}^{2}$ contact pads are defined by a polyimide shadow mask. We deposit a $5 \mathrm{~nm}$ thick chromium adhesion layer followed by a $25 \mathrm{~nm}$ thick gold film by electron-beam evaporation. For individual testing the stripes are separated by cutting the PDMS substrate, as shown in the inset of Fig. 1(a). Under the SEM, the surface of the as-fabricated film is covered with tribranched microcracks randomly distributed throughout the gold film. ${ }^{10}$ The gold ligaments that demarcate the cracks, however, form

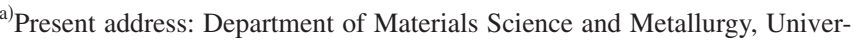
sity of Cambridge, Cambridge CB3 OFF, UK; electronic mail: spl37@cam.ac.uk
}

a network that percolates the whole film and maintains electrical conductance. The branches of the microcracks are $0.2-0.6 \mu \mathrm{m}$ long. The average spacing between the microcracks is a few tenths of a micrometer. We do not yet understand how these microcracks are formed. Crack geometry and density are reproducible from batch to batch.

A uniform test protocol is followed to observe changes in film structure. The conductors are stretched in cycles with a step-motor-driven, uniaxial electromechanical stretcher ${ }^{6}$ in two sequences. The stretcher applies instantaneous strain steps and measures electrical resistance. After each strain step, the sample is held stretched for $5 \mathrm{~min}$, and its electrical resistance $R$ is recorded every minute. The sample is elongated and relaxed once in $1 \%$ strain steps up to $32 \%$ and then back to $0 \%$. This priming cycle makes $R$ reproducible during later cycles. For further cycling the conductor is elongated from $0 \%$ to $32 \%$ and relaxed back to $0 \%$ strain in $8 \%$ strain steps. The variation of $R$ (normalized to its initial value $R_{\text {init }}$ ) during mechanical cycling is plotted in Fig. 1(b). The rise of $R$ between the priming and the following cycles indicates partial fracture of the conductor gold film. That the cycles of electrical resistance replicate the cycles of elongation is evident for cycles 92-101 from Fig. 1(c).

We study the microstructure of samples in the SEM before, during and after stretching. Figure 2(a) shows the surface of the film relaxed after the first, priming, cycle. Adjacent microcracks have coalesced to cracks of $1-2 \mu \mathrm{m}$ length that run roughly perpendicular to the stretching direction. Between these cracks, the gold film is intact. Figure 2(b) shows the surface of the conductor while stretched by $20 \%$ during the second cycle. The longer cracks have opened in the tensile direction (dark areas) but have not propagated. Delaminated metal film is seen as bright streaks. The delamination is caused by out-of-plane deflection of the film. Length and density of these long cracks remain the same after many cycles, as seen on the film relaxed after 101 cycles [Fig. 2(c)]. The longer cracks have again closed, delaminated margins of gold ligaments overlap, and a few longitudinal cracks were opened by lateral contraction. The microscale pattern of the gold network remains intact. In 
a.

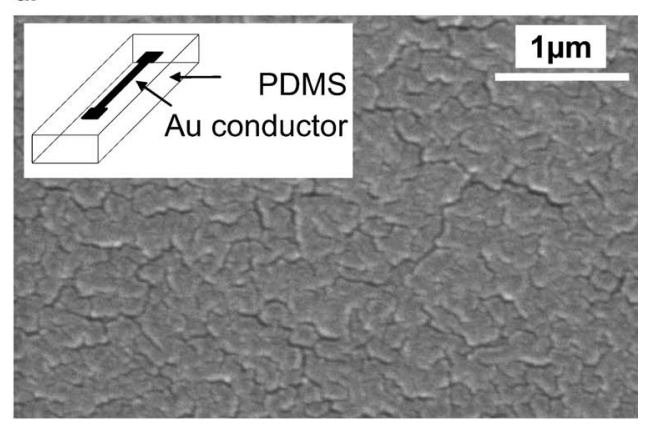

b.

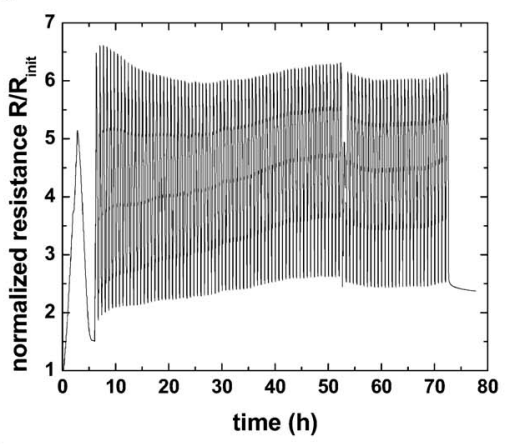

c.

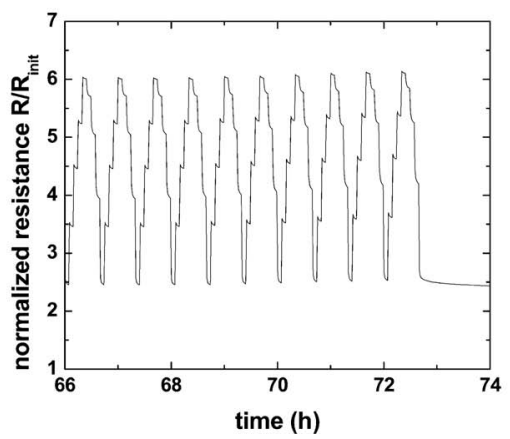

FIG. 1. (a) SEM micrograph of the as-prepared $25 \mathrm{~nm}$ thick gold film on PDMS. The gold ligaments percolate between the micron-size microcracks. Inset: Schematic of a gold conductor on PDMS. (b) and (c) Normalized electrical resistance of a gold conductor on PDMS under cyclic elongation of $32 \%$. The first cycle is performed in 5 min long $1 \%$ strain steps. Strain steps of $8 \%$ every $5 \mathrm{~min}$ are applied in the next 100 cycles (b). The resistance steps can be seen in the expanded view of the last 10 cycles (c).

essence, the gold film deformed only elastically over the many cycles to $32 \%$ maximum strain.

How can a thin metal film with distributed microcracks sustain cyclic stretching to $32 \%$ without fatigue? The answer lies in two factors: the microscale structure of the film, and the compliance of the substrate. The former factor can be visualized by a macroscopic experiment [Fig. 3(a)]. An array of tribranched cuts is made in a piece of transparency foil in the pattern of Fig. 3(b), and the foil is pulled at two opposite edges. The patterned foil elongates by deflecting and twisting out of the plane. The strain induced in the foil remains so small that it does not tear the foil. Upon release, the foil becomes flat again. This experiment illustrates a principle: a film of a stiff material can be made elastically stretchable if the film is suitably patterned.

The large foil is a macroscopic model for a freestanding film. Our microscopic evidence is taken on a gold film bonded to a PDMS substrate. How does the stretchability of the patterned stiff film depend on the compliance of the underlying substrate? If the substrate were stiff, it would conDownloaded 31 May 2006 to 131.111.49.250. Redistribution subject a.

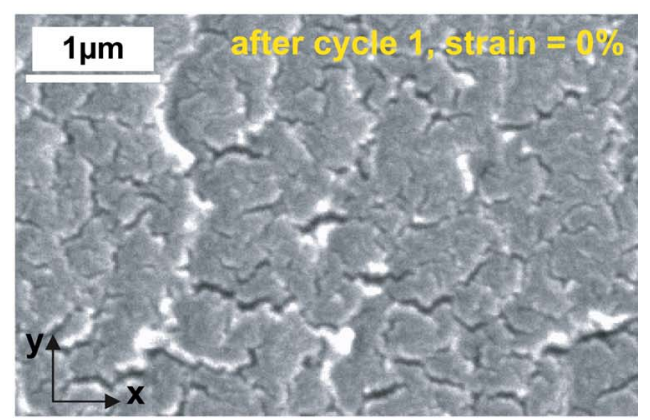

b.

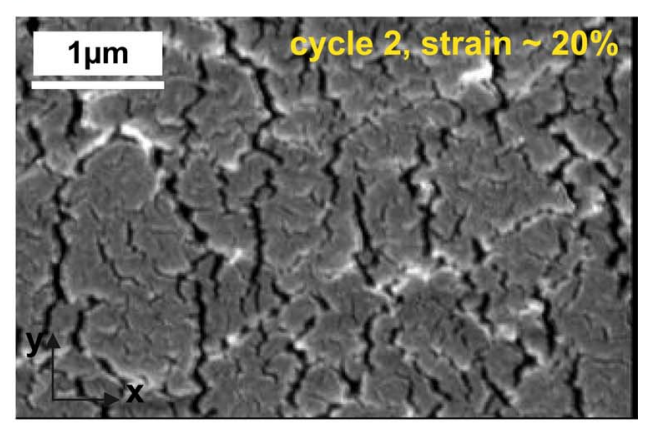

c.

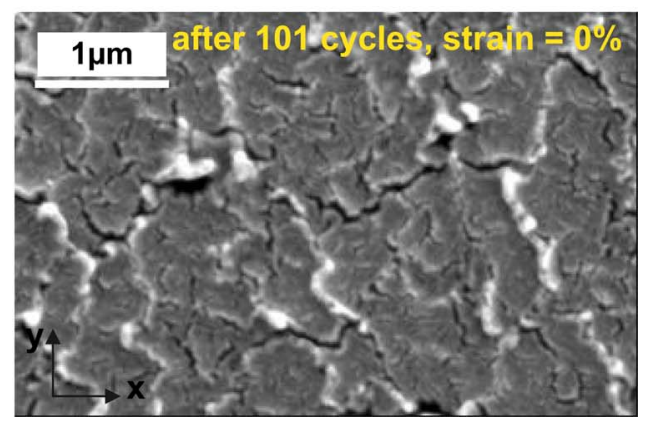

FIG. 2. (Color online) SEM micrographs of the gold percolating network with microcracks (a) at $0 \%$ elongation, after the priming cycle, (b) at $\sim 20 \%$ applied elongation during the second stretching cycle, and (c) at $0 \%$ elongation, after 101 cycles. The applied elongation is along the $x$ axis. Note that the micrographs were taken from three different samples.

fine the deformation of the film in its plane. In contrast, a sufficiently compliant substrate (e.g., PDMS) allows the microscopically patterned film to deform almost like the freestanding transparency foil: by deflecting and twisting out of the plane.

To quantify the strain levels in the stretchable film, we simulate the deformation of the patterned films as in Fig. 3(b) under elongation, using the finite element code ABAQUS. The centers of the tribranched cracks in Fig. 3(b) coincide with a hexagonal lattice of lattice spacing $L$. The branches of the $Y$-shaped cracks, of length $a$, lie along the lines that connect adjacent lattice points. Due to the symmetry of this pattern, we only simulate the shaded part of the film in Fig. 3(b), with displacement $u$ applied to the ligaments along the two parallel edges of the shaded area [Fig. $3(c)$ ]. To avoid confusion with the microscopic strain in the film, we call the quantity $2 u / L$ the relative elongation. The film is meshed with eight-node quadrilateral shell elements, with densified mesh near the crack tips. We model the film as a linear elastic material with Young's modulus $E$. In simulations, $a / L=0.75$ and $h / L=0.01$, where $h$ is the film thickness. Results are presented for the cell demarcated in Fig. to AIP license or copyright, see http://apl.aip.org/apl/copyright.jsp 
a.

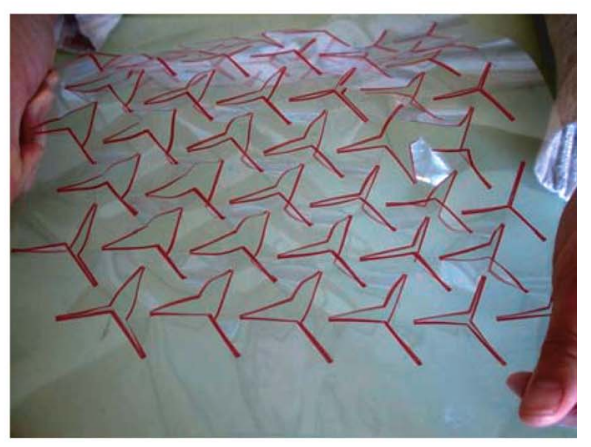

b.

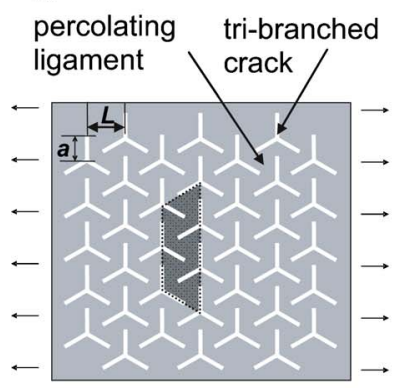

c.

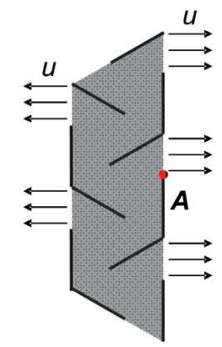

d.

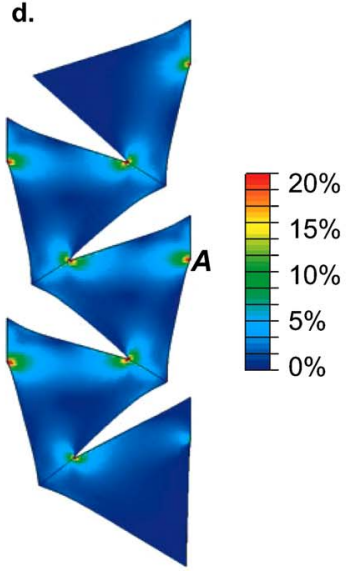

e.

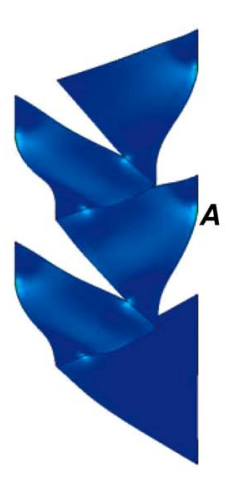

FIG. 3. (Color online) (a) Macroscopic visualization: a transparency foil patterned with tribranched cuts becomes stretchable by deflecting out of the plane. (b) Schematic of the film patterned with the tribranched cracks. (c) Simulation model [corresponding to the shaded part in (b)]. Under a relative elongation of $20 \%$, the percolating ligaments (d) bend in the plane, leading to the openings of the cracks, or (e) deflect and twist out of the plane. The shades indicate the levels of the larger principal strain in the film.

3 (c) at a relative (macroscopic) elongation of $20 \%$ [Figs. 3(d) and 3(e)]. At each point in the film the strain has two principal components, the larger of which is indicated by the shade in Figs. 3(d) and 3(e).

In Fig. 3(d) the deformation is confined in the plane, corresponding to the limiting case of a film on a rigid substrate. The film accommodates the elongation by in-plane

bending of the ligaments, which leads to the opening of the cracks and significant strain at the crack tips. In Fig. 3(e) the film can deflect and twist out of the plane, corresponding to the limiting case of a film on an infinitely compliant substrate. The film deforms as if it were held in air. A large elongation induces only small strain in the film. Most of the film deforms elastically under large elongation. Without much plastic deformation, the film can then be elongated repeatedly, and does not fatigue.

In summary, two combined features enable the reversible stretchability of thin gold films on PDMS: (i) elastomeric substrates are extremely compliant; (ii) a microcrack pattern in the metal film allows the film to elongate by deflecting and twisting out of plane, so that a large applied elongation only induces small and elastic strain in the film. As a result, the energy released at the crack tips is minimized, inhibiting crack growth across the metal film. Furthermore, because the metal film only deforms elastically, finite and reproducible electrical conduction is maintained over repeated deformation. The understanding of the high stretchability of micropatterned thin metal films on elastomeric substrates provides a general principle for the design of stretchable materials. Though much remains to be done to fully integrate electronic circuits on elastomeric substrates, the importance of stretchable device materials cannot be overstated, with application opportunities extending from large-area electronics to bioelectronic interfaces that take advantage of the mechanical matching between electronics and biological tissue.

This research was supported at Princeton University by DARPA-funded AFRL-managed Macroelectronics Program Contract No. FA8650-04-C-7101, and at Harvard University by the National Science Foundation through the MRSEC.

${ }^{1}$ D. W. Pashley, Proc. R. Soc. London, Ser. A 255, 218 (1960).

${ }^{2}$ H. Huang and F. Spaepen, Acta Mater. 48, 3261 (2000).

${ }^{3}$ S. L. Chiu, J. Leu, and P. S. Ho, J. Appl. Phys. 76, 5136 (2000).

${ }^{4}$ F. Macionczyk and W. Bruckner, J. Appl. Phys. 86, 4922 (1999).

${ }^{5}$ Y. Xiang, T. Li, Z. Suo, and J. J. Vlassak, Appl. Phys. Lett. 87, 161910 (2005).

${ }^{6}$ S. Périchon-Lacour, S. Wagner, Z. Huang, and Z. Suo, Appl. Phys. Lett. 82, 2404 (2003).

${ }^{7}$ S. P. Lacour, J. E. Jones, S. Wagner, T. Li, and Z. Suo, Proc. IEEE 93, 1459 (2005)

${ }^{8}$ D. S. Gray, J. Tien, and C. S. Chen, Adv. Mater. (Weinheim, Ger.) 16, 393 (2004).

${ }^{9}$ S. P. Lacour, S. Wagner, and Z. Suo, Mater. Res. Soc. Symp. Proc. 795, U.6.9.1 (2003).

${ }^{10}$ S. Wagner, H. Gleskova, I.-C. Cheng, J. C. Sturm, and Z. Suo, in Flexible Flat Panel Displays, edited by G. P. Crawford (Wiley, Chichester, 2005), pp. 263-283.

${ }^{11}$ V. J. Lumelsky, M. S. Shur, and S. Wagner, IEEE Sens. J. 1, 41 (2001).

${ }^{12}$ M. Maghribi, J. Hamilton, D. Polla, K. Rose, T. Wilson, and P. Krulevitch, Madison: Second Annual International IEEE-EMBS Special Topic Conference on Microtechnologies in Medicine and Biology (IEEE, New York, 2002), pp. 80-83.

${ }^{13}$ S. P. Lacour, C. Tsay, S. Wagner, Zhe Yu, and B. Morrison III, The Fourth IEEE Conference on Sensors, Irvine (IEEE, New York, 2005), pp. 617-620. 